\title{
Risk factors and screening timing for developmental dysplasia of the hip in preterm infants
}

\author{
Ga Won Jeon, MD, PhD ${ }^{1}$, Hye Jung Choo, MD, PhD², Yong Uk Kwon, MD, PhD ${ }^{3}$ \\ ${ }^{1}$ Department of Pediatrics, Inha University Hospital, Inha University College of Medicine, Incheon, Korea; ${ }^{2}$ Department of Radiology, Inje University Busan Paik \\ Hospital, Inje University College of Medicine, Busan, Korea; ${ }^{3}$ Department of Orthopaedic Surgery, Inje University Busan Paik Hospital, Inje University College of \\ Medicine, Busan, Korea
}

Background: The delayed diagnosis of developmental dys plasia of the hip (DDH) requires complex treatment and sometimes progresses to hip osteoarthritis.

Purpose: This study aimed to evaluate the risk factors and screening time for DDH in preterm infants.

Methods: A total of 155 preterm infants with a gestational age $<32$ weeks screened for DDH with ultrasonography were enrolled in this retrospective chart review.

Results: The incidence of DDH was 6.45\% (10 of 155). Gestational age, birth weight, sex ratio, and breech presentation did not differ significantly between infants treated for $\mathrm{DDH}(\mathrm{n}=10)$ and nontreated infants $(n=145)$ (gestational age, 29.2 \pm 1.4 weeks vs. $29.6 \pm 2.0$ weeks, $P=0.583$; birth weight, $1,240 \pm 237$ g vs. $1,295 \pm 335 \mathrm{~g}, P=0.607$; female sex, 7 of $10(70.0 \%)$ vs. 77 of 145 (53.1\%), $P=0.346$; and breech presentation, 5 of $10(50.0 \%)$ vs. 43 of 145 (29.7\%), $P=0.286$, respectively). Performing the first ultrasonography earlier than 38 weeks of postmenstrual age (PMA) increased the risk of an abnormal finding by 3.76 times compared to performing it at $\geq 38$ weeks of PMA. These abnormal findings on ultrasonography resolved spontaneously. Breech presentation increased the risk of minor abnormal findings on the first ultrasonography by 3.11 times versus nonbreech presentation and resolved spontaneously. $\mathrm{DDH}$ in preterm infants did not occur predominantly on the left side or in infants born with breech presentation.

Conclusion: Performing ultrasonography screening earlier than 38 weeks of PMA caused unnecessary subsequent ultrasonography and overtreatment. Breech presentation was not a risk factor for DDH in preterm infants. However, breech presentation could increase the risk of minor abnormal findings at the 1st ultrasonography compared to nonbreech presentation, which resolved spontaneously. The etiology and risk factors for DDH in preterm infants are somewhat different from those for DDH in term infants.

Key words: Breech presentation, Developmental dysplasia of the hip, Premature Infant, Hip Osteoarthritis, Ultrasonography

\section{Key message}

Question: When is the best screening timing and what is the risk factor for developmental dysplasia of the hip (DDH) in preterm infants?

Finding: Ultrasonography performed earlier than 38 weeks of postmenstrual age caused unnecessary subsequent ultrasonography. DDH did not occur predominantly on the left side or in breech infants.

Meaning: The screening timing, etiology, and risk factors for $\mathrm{DDH}$ in preterm infants are somewhat different from those in term infants.

\section{Introduction}

Developmental dysplasia of the hip (DDH) is caused by the abnormal relationship between the femoral head and the acetabulum of the immature hip. DDH includes wide spectrum of clinical manifestations from mild dislocation to frank dislocation. So, the incidence of DDH is variable. Subluxated hip was detected in $1 \%$ and dislocated hip was detected in $0.1 \%$ of newborn infants. ${ }^{1)}$ In another study, DDH was detected to $1.5 \%$ $4.9 \%$ in term infants, ${ }^{2)}$ whereas, immature hip or unstable hip was detected up to $15 \%$ by imaging studies. ${ }^{3)}$ The pathogenesis of DDH is multifactorial. Breech presentation with knee extension in utero can cause continuous hamstring forces on the hip, which is the most important single risk factor of DDH. Other important risk factors of DDH include female, family history of DDH, first-born. ${ }^{4,5)}$ neuromuscular disorders, such as arthrogryposis, or tight swaddling after birth placing hips into prolonged adduction. $\left.{ }^{6}\right)$

It is widely believed that early diagnosis and treatment of DDH are essential for good outcome of the hip to prevent hip osteoarthritis in adulthood. Delayed diagnosis requires complex treatment with a poor outcome of the hip.

Ultrasonography is the gold standard with high sensitivity and specificity in an infant younger than 4 months whose hip is cartilaginous interfering radiologic visualization of the femoral

Corresponding author: Ga Won Jeon, Department of Pediatrics, Inha University Hospital, Inha University College of Medicine, 27 Inhang-ro, Jung-gu, Incheon 22332, Korea 凶iamgawon@hanmail.net, https://orcid.org/0000-0002-8206-9727

Received: 31 July, 2021, Revised: 7 October, 2021, Accepted: 12 October, 2021

This is an open-access article distributed under the terms of the Creative Commons Attribution Non-Commercial License (http://creativecommons.org/licenses/bync/4.0/) which permits unrestricted non-commercial use, distribution, and reproduction in any medium, provided the original work is properly cited.

Copyright (c) 2022 by The Korean Pediatric Society 


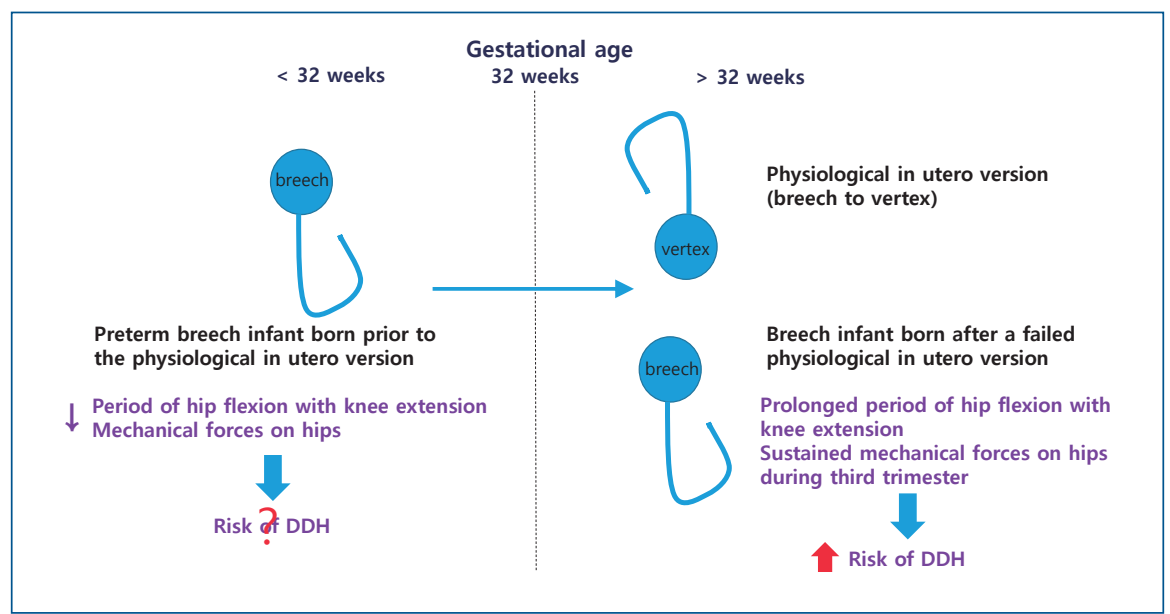

Graphical abstract. Physiological in utero version of the fetus from breech to vertex presentation occurs by a gestational age (GA) of 32 weeks. Preterm breech infants prior to this physiological in utero version are exposed to less and shorter durations of mechanical forces predisposing them to developmental dysplasia of the hip (DDH) than infants with a persistent breech presentation after failure of physiological in utero version. Thus, the risk factors for DDH of preterm breech infants ( $G A<32$ weeks) born prior to physiological in utero version differ from those of breech infants (GA $\geq$ 32 weeks) born after failed in utero version.

head. ${ }^{4)}$ However, ultrasonography as early as within the first 4 weeks after birth often discloses the presence of minor instability or immaturity of the hip, which resolves spontaneously in a few weeks later. $\left.{ }^{6}\right)$ Thus, performing ultrasonography too early can cause overtreatment. The proper timing of screening for DDH is still controversial. Kolb et al. ${ }^{7}$ have recommended 6-8 weeks after birth, not within the first 2 weeks after birth.

In preterm infants, DDH is not well defined yet. Some studies advocate that DDH is associated with preterm delivery, ${ }^{8,9)}$ while others do not. ${ }^{10,11)}$ The relationship between preterm delivery and DDH remains controversial. Whether breech presentation is a risk factor of DDH in preterm infants as term infants remains unclear. The fetus usually undergoes physiological in utero version from breech to vertex presentation by gestational age (GA) of 32 weeks. Preterm breech infants prior to this physiological in utero version are exposed to less and shorter duration of mechanical forces predispose to DDH than infants with persistent breech presentation after failure of physiological in utero version. ${ }^{12)}$ Thus, breech presentation in preterm infants is somewhat different from that in term infants. The aim of this study was to determine risk factors and proper screening time of DDH in preterm infants.

\section{Methods}

This study was reviewed and approved by the Institutional Review Board (IRB) of Inje University Busan Paik Hospital (identification code: 2020-12-003) in accordance with the Declaration of Helsinki. The IRB waived the need for informed consent for this retrospective chart review. Medical records of 214 preterm infants with $\mathrm{GA}<32$ weeks who were admitted to Inje University Busan Paik Hospital from September 2017 to December 2020 were reviewed. Preterm infants who were not screened for DDH

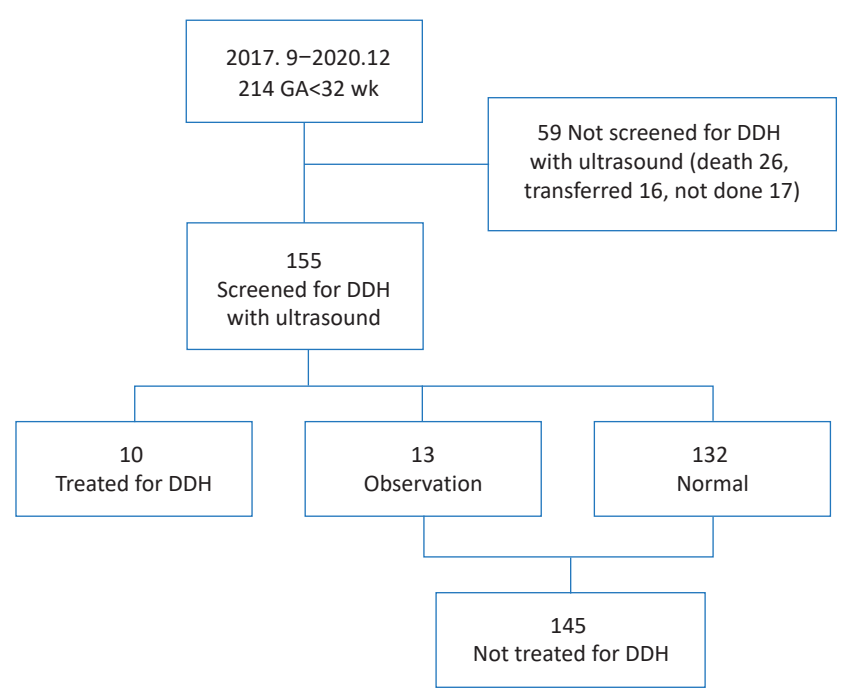

Fig. 1. Flow chart showing the patient selection process. Among the 214 preterm infants with a GA<32 weeks admitted between September 2017 and December 2020, 59 were excluded because they were transferred to other hospitals (16 infants), died (26 infants), or were not screened (17 infants). Ten of the 155 infants were assigned to the treated group, 13 were assigned to the observation group, and 132 were assigned to the normal group. Finally, 10 infants were treated for DDH, while 145 (observation and normal groups) were not treated for DDH. GA, gestational age; $\mathrm{DDH}$, developmental dysplasia of the hip.

with ultrasonography (59 infants) were excluded because they were transferred to other hospitals (16 infants), died (26 infants), or not screened (17 infants) (Fig. 1).

Hip ultrasonography images were obtained using a $15-7 \mathrm{MHz}$ linear array transducer or a $12-5 \mathrm{MHz}$ linear array transducer (iU22; Philips Medical Systems, Bothell, WA, USA). Ultrasonography results were reported by radiologist as depth of the bony acetabulum and coverage of femoral head by acetabulum by Graf classification. ${ }^{13)}$ Graf classification was mainly based on $\alpha$ angle, although it was also based on $\beta$ angle and age of the patient. ${ }^{14,15)}$ 
The pediatric orthopedic surgeon decided the treatment for DDH based on the ultrasonography result, clinical examination, and age of the patient. The treated group was treated for $\mathrm{DDH}$ with Pavlik harness. Ultrasonography was performed in 3 weeks after applying Pavlik harness. If the hip became clinically stable with Pavlik harness, it was applied for 6 more weeks, then tapered. Hip radiograph was taken at 6 months after successful Pavlik harness treatment. The observation group included infants with minor abnormal findings at the 1st ultrasonography which resolved spontaneously at the 2nd ultrasonography without treatment. The normal group included infants whose 1st ultrasonography was normal. Both the observation group and the normal group were not treated for DDH. The normal group was not performed the 2nd ultrasonography because the 1st ultrasonography was normal.

Demographic factors such as GA, birth weight, gender, and breech presentation were compared among groups. Postnatal day of 1st and 2nd ultrasonography and postmenstrual age (PMA) of 1 st and 2nd ultrasonography were also compared among groups.

For continuous variables with a normal distribution and homogeneous variance, $t$ test was performed for comparison between the 2 groups and analysis of variance with Bonferroni correction was performed for comparison among multiple groups. For variables without a normal distribution or without homogeneous variance, Mann-Whitney $U$ test was performed for comparison between the 2 groups while the Kruskal-Wallis test was performed for comparison among multiple groups. For nominal variables, chi-square test or Fisher exact test was performed. We evaluated the odds ratios (ORs) with 95\% confidence interval (CI) using logistic regression analyses to assess associations between risk factors and DDH. All statistical analyses were performed using IBM SPSS Statistics ver. 25.0 (IBM Co., Armonk, NY, USA). $P$ values of $<0.05$ were considered significant. Data are given as mean \pm standard deviation or frequencies (percentages).

\section{Results}

Ten of 155 infants were treated for DDH (treated group) (Fig. 1). Thirteen of 155 infants were assigned to the observation group and 132 of 155 were assigned to the normal group at the 1st ultrasonography. Finally, 10 infants were treated for DDH while 145 were not. The incidence of DDH was $6.45 \%$ (10 of 155). The incidence of breech presentation was $31 \%$ (48 of 155 ) in preterm infants with $\mathrm{GA}<32$ weeks.

\section{Characteristics of the observation versus normal groups (Table 1)}

GA, birth weight, and sex ratio were not significantly different between the observation group $(n=13)$ and the normal group $(\mathrm{n}=132)(\mathrm{GA}, 29.5 \pm 1.7$ weeks vs. $29.6 \pm 2.1$ weeks, $P=0.984$; birth weight, $1,269 \pm 278 \mathrm{~g}$ vs. $1298 \pm 341 \mathrm{~g}, P=0.615$; female,
9 of $13(69.2 \%)$ vs. 68 of 132 (51.5\%), $P=0.222$, respectively). Breech presentation was more frequent in the observation group than in the normal group (7 of 13 [53.9\%] vs. 36 of 132 [27.3\%], $P=0.045)$. Breech presentation increased the risk of abnormal finding at the 1st ultrasonography compared to nonbreech presentation (OR, 3.11; 95\% CI, 1.047-9.882). The time of the 1st ultrasonography screening was not different between the 2 groups ( $59 \pm 20$ days vs. $65 \pm 26$ days, $P=0.327$ ). However, more infants were performed the 1st ultrasonography earlier than 38 weeks of PMA in the observation group than in the normal group $(76.9 \%$ vs. $47.0 \%, P=0.039)$. Performing the 1st ultrasonography earlier than 38 weeks of PMA increased the risk of abnormal finding compared to performing the 1st ultrasonography at $\geq 38$ weeks of PMA (OR, 3.76; 95\% CI, 1.06114.297). Minor abnormal findings in the observation group resolved spontaneously at the 2 nd ultrasonography.

\section{Characteristics of treated versus nontreated infants (Table 2)}

GA and birth weight were not significantly different between infants treated for DDH $(n=10)$ and nontreated infants $(n=$ 145) (29.2 \pm 1.4 weeks vs. $29.6 \pm 2.0$ weeks, $P=0.583$ and $1,240 \pm$ $237 \mathrm{~g}$ vs. $1,295 \pm 335 \mathrm{~g}, P=0.607$, respectively). Sex ratio and breech presentation were not significantly different between the

Table 1. Characteristics of the observation versus normal groups

\begin{tabular}{|c|c|c|c|}
\hline & Observation $(n=13)$ & Normal $(n=132)$ & $P$ value \\
\hline Gestational age (wk) & $29.5 \pm 1.7$ & $29.6 \pm 2.1$ & $0.984^{a)}$ \\
\hline$<28$ & $3(23.1)$ & $33(25.0)$ & $>0.999^{b)}$ \\
\hline$\geq 28$ & $10(76.9)$ & $99(75.0)$ & \\
\hline$<30$ & $8(61.5)$ & $60(45.5)$ & $0.268^{c)}$ \\
\hline$\geq 30$ & $5(38.5)$ & $72(54.6)$ & \\
\hline$<31$ & $10(76.9)$ & $84(63.6)$ & $0.544^{b)}$ \\
\hline$\geq 31$ & $3(23.1)$ & $48(36.4)$ & \\
\hline Body weight (kg) & $1,269 \pm 278$ & $1,298 \pm 341$ & $0.615^{d)}$ \\
\hline$<1$ & $2(15.4)$ & $29(22.0)$ & $0.735^{\mathrm{b})}$ \\
\hline$\geq 1$ & $11(84.6)$ & $103(78.0)$ & \\
\hline$<1.5$ & $12(92.3)$ & $89(67.4)$ & $0.110^{b)}$ \\
\hline$\geq 1.5$ & $1(7.7)$ & $43(32.6)$ & \\
\hline Female sex & $9(69.2)$ & $68(51.5)$ & $0.222^{c)}$ \\
\hline Breech & $7(53.9)$ & $36(27.3)$ & $0.045^{c)}$ \\
\hline USG1_d (day) & $59 \pm 20$ & $65 \pm 26$ & $0.327^{\mathrm{a})}$ \\
\hline USG1_PMA (wk) & $38.0 \pm 2.2$ & $38.9 \pm 2.5$ & $0.132^{\mathrm{d})}$ \\
\hline$<37$ & $5(38.5)$ & $28(21.2)$ & $0.172^{b)}$ \\
\hline$\geq 37$ & $8(61.5)$ & $104(78.8)$ & \\
\hline$<38$ & $10(76.9)$ & $62(47.0)$ & $0.039^{c)}$ \\
\hline$\geq 38$ & $3(23.1)$ & $70(53.0)$ & \\
\hline$<40$ & $11(84.6)$ & 94 (71.2) & $0.516^{b)}$ \\
\hline$\geq 40$ & $2(15.4)$ & $38(28.8)$ & \\
\hline USG2_d (day) & $97 \pm 27$ & - & \\
\hline USG2_PMA (wk) & $43.3 \pm 2.9$ & - & \\
\hline
\end{tabular}

Values are presented as mean \pm standard deviation or number (\%). USG1_d, postnatal day of first ultrasonography; USG1_PMA, postmenstrual age at first ultrasonography; USG2_d, postnatal day of second ultrasonography; USG2_PMA, postmenstrual age of second ultrasonography.

${ }^{a)} t$ test, ${ }^{\text {b) }}$ Fisher exact test, ${ }^{\mathrm{c})}$ Chi-square test, ${ }^{\mathrm{d})}$ Mann-Whitney $U$ test. 
2 groups (7 of 10 [70.0\%] vs. 77 of 145 [53.1\%], $P=0.346$ and 5 of 10 [50.0\%] vs. 43 of 145 [29.7\%], $P=0.286$, respectively). Postnatal day of the 1st ultrasonography and PMA of the 1st ultrasonography were similar between treated and nontreated infants $(P=0.865$ and $P=0.732$, respectively).

\section{Characteristics of the treated versus observation groups (Table 3)}

GA and birth weight were not significantly different between the treated group $(n=10)$ and the observation group $(n=13)$ ( $29.2 \pm 1.4$ weeks vs. $29.5 \pm 1.7$ weeks, $P=0.594$ and $1,240 \pm 236$ g vs. $1,269 \pm 278 \mathrm{~g}, P=0.728)$. Sex ratio and breech presentation were not significantly different between the 2 groups ( 7 of 10 [70.0\%] vs. 9 of 13 [69.2\%], $P>0.999$ and 5 of 10 [50.0\%] vs. 7 of 13 [53.8\%], $P>0.999$ ). Postnatal day of the 1 st ultrasonography screening and PMA of the 1st ultrasonography screening were not significantly different between the 2 groups $(63 \pm 17$ days vs. $59 \pm 20$ days, $P=0.599$ and $38.2 \pm 1.7$ weeks vs. $38.0 \pm$ 2.2 weeks, $P=0.385$, respectively).

Table 2. Characteristics of treated versus nontreated infants

\begin{tabular}{|c|c|c|c|}
\hline Characteristic & $\begin{array}{c}\text { Treated } \\
(n=10)\end{array}$ & $\begin{array}{c}\text { Nontreated } \\
\text { (observation and normal) } \\
(n=145)\end{array}$ & $P$ value \\
\hline Gestational age (wk) & $29.2 \pm 1.4$ & $29.6 \pm 2.0$ & $0.583^{\mathrm{a})}$ \\
\hline$<28$ & $2(20.0)$ & $36(24.8)$ & $>0.999^{b)}$ \\
\hline$\geq 28$ & $8(80.0)$ & $109(75.2)$ & \\
\hline$<30$ & $7(70.0)$ & 68 (46.9) & $0.199^{b)}$ \\
\hline$\geq 30$ & $3(30.0)$ & $77(53.1)$ & \\
\hline$<31$ & $9(90.0)$ & $94(64.8)$ & $0.166^{\mathrm{b})}$ \\
\hline$\geq 31$ & $1(10.0)$ & $51(35.2)$ & \\
\hline Body weight (kg) & $1,240 \pm 237$ & $1,295 \pm 335$ & $0.607^{c)}$ \\
\hline$<1$ & $1(10.0)$ & $31(21.4)$ & $0.689^{b)}$ \\
\hline$\geq 1$ & $9(90.0)$ & $114(78.6)$ & \\
\hline$<1.5$ & $9(90.0)$ & $101(69.7)$ & $0.283^{b)}$ \\
\hline$\geq 1.5$ & $1(10.0)$ & $44(30.3)$ & \\
\hline Female sex & $7(70.0)$ & $77(53.1)$ & $0.346^{\text {b) }}$ \\
\hline Breech & $5(50.0)$ & $43(29.7)$ & $0.286^{b)}$ \\
\hline USG1_d (day) & $63 \pm 17$ & $65 \pm 26$ & $0.865^{\mathrm{a})}$ \\
\hline USG1_PMA (wk) & $38.2 \pm 1.7$ & $38.8 \pm 2.5$ & $0.732^{\mathrm{c})}$ \\
\hline$<37$ & $2(20.0)$ & $33(22.8)$ & $>0.999^{b)}$ \\
\hline$\geq 37$ & $8(80.0)$ & $112(77.2)$ & \\
\hline$<38$ & $5(50.0)$ & $72(49.7)$ & $>0.999^{b)}$ \\
\hline$\geq 38$ & $5(50.0)$ & $73(50.3)$ & \\
\hline$<40$ & $8(80.0)$ & $105(72.4)$ & $0.730^{\mathrm{b})}$ \\
\hline$\geq 40$ & $2(20.0)$ & $40(27.6)$ & \\
\hline USG2_d (day) & $98 \pm 23$ & $97 \pm 27(\mathrm{~N}=13)$ & $0.933^{\mathrm{a})}$ \\
\hline USG2_PMA (wk) & $43.2 \pm 2.2$ & $43.3 \pm 2.9(\mathrm{~N}=13)$ & $0.894^{a)}$ \\
\hline
\end{tabular}

Values are presented as mean \pm standard deviation or number (\%).

USG1_d, postnatal day of first ultrasonography; USG1_PMA, postmenstrual age at first ultrasonography; USG2_d, postnatal day of second ultrasonography; USG2_PMA, postmenstrual age of second ultrasonography.

${ }^{\text {a) }} t$ test, ${ }^{\text {b) }}$ Fisher exact test, ${ }^{c}$ Mann-Whitney $U$ test.

\section{Characteristics of the treated group (Table 4)}

Breech presentation was not dominant in preterm infants treated for DDH (breech: 5 of 10, nonbreech: 5 of 10). DDH did not occur predominantly in the left side among preterm infants treated for DDH (left:right:both=4:3:3). There were 7 female infants and 3 male infants. Among 10 treated infants, there were 3 female infants with breech presentation.

\section{Discussion}

Performing ultrasonography screening earlier than 38 weeks of PMA increased the detection rate of minor abnormal findings which resolved spontaneously and overtreatment in preterm infants in this study. Younger GA, smaller birth weight, and breech presentation were not the risk factors for DDH in preterm infants in this study.

Breech presentation is the most important single risk factor of $\mathrm{DDH} .{ }^{3)}$ Breech infants remain at risk of developing $\mathrm{DDH}$ despite a normal screening ultrasound. ${ }^{16)}$ Thus, breech infants with normal ultrasonography are recommended to follow-up supplemental $\mathrm{x}$-ray at 4-6 months after birth because of the risk of subsequent dysplasia by Imrie et al. ${ }^{17)}$ The incidence of breech presentation was $31 \%$ in preterm infants with $\mathrm{GA}<32$ weeks in the present study. The incidence of breech presentation was $1 \%-3 \%$ at term, $7 \%$ at GA of 32 weeks, and $22 \%$ at GA of 28 weeks in a previous study. ${ }^{12}$

Physiological in utero version of the fetus from breech to vertex presentation occurs by GA of 32 weeks. Enrolled infants in this

Table 3. Characteristics of the treated versus observation groups

\begin{tabular}{|c|c|c|c|}
\hline & Treated $(n=10)$ & Observation $(n=13)$ & $P$ value \\
\hline Gestational age (wk) & $29.2 \pm 1.4$ & $29.5 \pm 1.7$ & $0.594^{a)}$ \\
\hline$<28$ & $2(20.0)$ & $3(23.1)$ & $>0.999^{\mathrm{b})}$ \\
\hline$\geq 28$ & $8(80.0)$ & $10(76.9)$ & \\
\hline$<30$ & $7(70.0)$ & $8(61.5)$ & $>0.999$ \\
\hline$\geq 30$ & $3(30.0)$ & $5(38.5)$ & \\
\hline$<31$ & $9(90.0)$ & $10(76.9)$ & $0.604^{b)}$ \\
\hline$\geq 31$ & $1(10.0)$ & $3(23.1)$ & \\
\hline Body weight (kg) & $1,240 \pm 236$ & $1,269 \pm 278$ & $0.728^{c)}$ \\
\hline$<1$ & $1(10.0)$ & $2(15.4)$ & $>0.999^{b)}$ \\
\hline$\geq 1$ & $9(90.0)$ & $11(84.6)$ & \\
\hline$<1.5$ & $9(90.0)$ & $12(92.3)$ & $>0.999^{b)}$ \\
\hline$\geq 1.5$ & $1(10.0)$ & $1(7.7)$ & \\
\hline Female sex & $7(70.0)$ & $9(69.2)$ & $>0.999^{b)}$ \\
\hline Breech & $5(50.0)$ & $7(53.8)$ & $>0.999^{b)}$ \\
\hline USG1_d (day) & $63 \pm 17$ & $59 \pm 20$ & $0.599^{a)}$ \\
\hline USG1_PMA (wk) & $38.2 \pm 1.7$ & $38.0 \pm 2.2$ & $0.385^{c)}$ \\
\hline USG2_d (day) & $98 \pm 23$ & $97 \pm 27$ & $0.931^{a)}$ \\
\hline USG2_PMA (wk) & $43.2 \pm 2.2$ & $43.3 \pm 2.9$ & $0.887^{a)}$ \\
\hline
\end{tabular}

Values are presented as mean \pm standard deviation or number (\%).

USG1_d, postnatal day of first ultrasonography; USG1_PMA, postmenstrual age at first ultrasonography; USG2_d, postnatal day of second ultrasonography; USG2_PMA, postmenstrual age of second ultrasonography.

${ }^{\text {a) }} t$ test, ${ }^{\text {b) }}$ Fisher exact test, ${ }^{c}$ Mann-Whitney $U$ test. 
study were preterm infants with $\mathrm{GA}<32$ weeks who were born before in utero version. Thus, the incidence of breech presentation was higher in this study with infants of $\mathrm{GA}<32$ weeks than in other studies with infants of $G A \geq 32$ weeks. However, preterm infants are exposed to less and shorter duration of mechanical forces on hips during the third trimester to develop DDH. ${ }^{12)}$ As a result, breech presentation was not a risk factor of DDH in preterm infants in this study. Half infants with DDH had breech presentation while half infants with DDH had nonbreech presentation in this study. Although breech presentation increased the risk of abnormal finding at the 1st ultrasonography compared to nonbreech presentation among nontreated infants in this study, these minor abnormal findings resolved spontaneously. Lee et al. ${ }^{12)}$ have reported that DDH in very preterm breech infants (GA $<32$ weeks) born prior to the physiological in utero version is different from that in preterm breech infants (GA of 32 weeks to $<37$ weeks) born after a failed in utero version. They found that preterm breech infants with $\mathrm{GA}<32$ weeks had less ultrasonography findings for DDH than those with GA of 32 weeks to $<37$ weeks and that all abnormal findings in preterm breech infants with $G A<32$ weeks resolved spontaneously without treatment. ${ }^{12)}$ On the contrary, some researchers have reported that preterm breech infants have a similar incidence of DDH to term breech infants. All breech infants are recommended to be screened for DDH regardless of GA. ${ }^{18,19)}$ The risk for DDH in preterm breech infants was similar to that in term breech infants (OR, 1.27; 95\% CI, 0.25-6.40). ${ }^{19)}$ D'Alessandro and Dow ${ }^{20)}$ have also reported that GA does not seem to influence the incidence of DDH in breech presentation.

The left hip has a 3-fold increased risk of DDH compared to the right hip because the left hip lying posteriorly against the mother's spine undergoes sustained mechanical forces to limit abduction of the left hip. ${ }^{6}$ However, DDH did not occur in the left side predominantly in this study (left:right:both $=4: 3: 3$ ). It can be explained by the small sample size of this study with selection bias. However, it can also be explained by the fact that preterm infants are exposed to less and shorter duration of mechanical forces to develop DDH of the left hip because they are born prematurely. $\left.{ }^{6}\right)$

In this study, GA and birth weight were not smaller in infants treated for DDH. In addition, smaller GA and birth weight were not risk factors of DDH in preterm infant with $\mathrm{GA}<32$ weeks. There are still controversies about whether preterm is a risk factor of DDH. DDH is not well defined in preterm infants. The incidence of $\mathrm{DDH}$ and hip pathologies increased as GA decreased. 9) Prematurity has been suggested as a risk factor of $\left.\mathrm{DDH} .{ }^{8}\right) \mathrm{A}$ systemic review has concluded that low birth weight and preterm birth are potential risk factors of hip bone abnormalities and hip osteoarthritis in adulthood. ${ }^{21)}$ On the other hand, prematurity did not increase the risk of DDH in other studies. ${ }^{10,11)}$ Rather, preterm infants have significantly lower rate of immature hips compared to term infants, suggesting that prematurity is not a predisposing factor for $\mathrm{DDH} .{ }^{22)}$ Lange et al. ${ }^{2}$ have reported that preterm infants have a decreased risk of DDH than term infants. Also, the incidence of mature hip was twice as high in preterm infants than in term infants. ${ }^{2)}$ Lange et al..$^{2}$ have suggested that these findings are caused by the absence of intrauterine risk factors occurring during the third trimester such as less intrauterine space and breech presentation causing mechanical forces on hips during the third trimester.

In this study, ultrasonography screening was done at around 38-39 weeks of PMA. However, more infants in the observation group than in the normal group were performed ultrasonography earlier than 38 weeks of PMA. This might be why there were minor abnormal findings in the observation group which resolved spontaneously. These results suggest that the incidence of DDH is also influenced by the PMA of ultrasonography screening. If ultrasonography is performed too early, it can increase the detection rate of minor instability or minor abnormal findings of the hip and the risk of overtreatment. ${ }^{23)}$ Minor instability of the hip during early postnatal period usually resolves spontaneously without treatment. Shaw and Segal ${ }^{3)}$ have concluded that selective ultrasonography is recommended for infants with breech presentation and a family history of DDH after 6 weeks of age. Female infants with breech presentation and a family history of $\mathrm{DDH}$ are recommended to undergo ultrasonography screening for DDH at 4-6 weeks after birth, not before 4 weeks of age. ${ }^{24,25)}$ Kolb et $\mathrm{al.}^{7}$ ) have recommended universal ultrasonography screening for $\mathrm{DDH}$ at 6-8 weeks after birth. As mentioned before, the time of ultrasonography screening for term infants

Table 4. Characteristics of the treated group

\begin{tabular}{lclclll}
\hline GA (wk) & BW $(\mathrm{g})$ & Sex & Delivery mode & Presentation & Laterality & Ultrasonography findings \\
\hline 27.6 & 1,200 & Female & C/Sec & Transverse & Left & $\alpha$ angle: $56^{\circ}-58^{\circ}$ \\
28.7 & 1,400 & Male & C/Sec & Breech & Left & $\alpha$ angle: $53^{\circ}-55^{\circ}$ \\
28.1 & 1,300 & Female & PSD & Breech & Both & Undercoverage of the bilateral femoral heads (50\%) \\
28.7 & 1,100 & Male & C/Sec & Transverse & Right & $\alpha$ angle: $57^{\circ}-60^{\circ}$ \\
30.3 & 1,200 & Female & C/Sec & Cephalic & Both & Lateral subluxation of the bilateral hip joints $^{\circ}$ \\
29.9 & 1,600 & Male & C/Sec & Breech & Right & $\alpha$ angle: $50^{\circ}-55^{\circ}$ \\
27.0 & 700 & Female & $\mathrm{C} / \mathrm{Sec}$ & Breech & Right & $\alpha$ angle: $55^{\circ}$ \\
29.9 & 1,200 & Female & $\mathrm{C} / \mathrm{Sec}$ & Breech & Left & $\alpha$ angle: $55^{\circ}$ \\
30.7 & 1,400 & Female & PSD & Cephalic & Left & $\alpha$ angle: $55^{\circ}$ \\
31.1 & 1,300 & Female & $\mathrm{C} / \mathrm{Sec}$ & Cephalic & Both & $\alpha$ angle: $55^{\circ}-58^{\circ}$, Highly suspicious immature hip \\
\hline
\end{tabular}

$\mathrm{GA}$, gestational age; $\mathrm{BW}$, birth weight; $\mathrm{C} / \mathrm{Sec}$, cesarean section delivery; $\mathrm{PSD}$, preterm spontaneous delivery. 


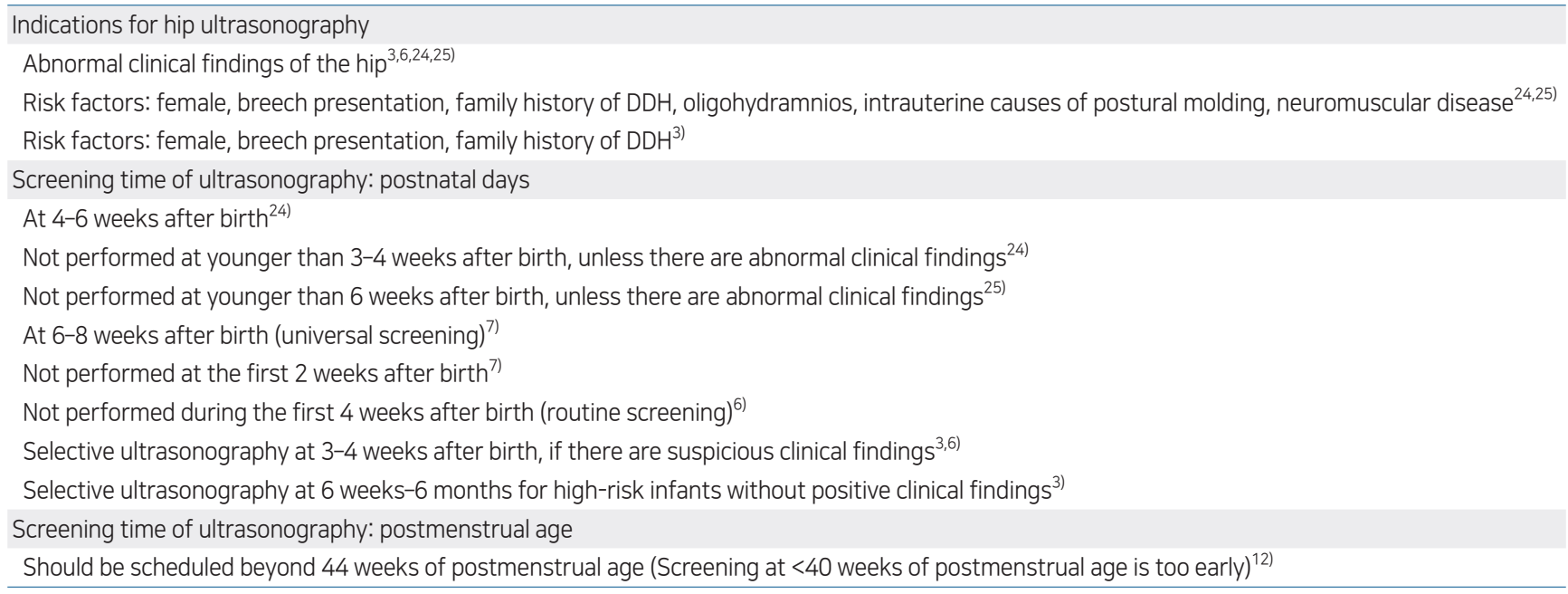

varies according to centers. Furthermore, the time of ultrasonography screening for preterm infants is not established yet. Lee at al. ${ }^{12)}$ have recommended ultrasonography screening for preterm infants $\geq 44$ weeks of PMA. They concluded that ultrasonography screening $<40$ weeks of PMA had 8 times increased risk of abnormal ultrasonography findings for $\mathrm{DDH}$ compared to screening $\geq 44$ weeks of PMA, which did not persist on the following ultrasonography. Recommended indications and screening timing for hip ultrasonography are in Table 5 .

The present study has some limitations. First, we could not figure out the medical records whether there were abnormal clinical findings of the hip or not, because of the retrospective nature of this study. Second, this study is a single-center study with a small sample size, especially in the subgroup analysis, which might have an adverse effect on the statistical power.

In conclusion, performing ultrasonography screening earlier than 38 weeks of PMA could cause unnecessary subsequent ultrasonography and overtreatment in preterm infants. Smaller GA and birth weight were not risk factors of DDH in preterm infants. Breech presentation was not a risk factor for DDH in preterm infants, although it could increase the risk of minor abnormal findings at the 1st ultrasonography compared to nonbreech presentation. DDH in preterm infants did not occur predominantly at the left side. Thus, DDH in preterm infants is somewhat different from DDH in term infants. Further studies are required to make guidelines of the indication and screening time of ultrasonography for preterm infants.

\section{Footnotes}

Conflicts of interest: No potential conflict of interest relevant to this article was reported.

Funding: This study received no specific grant from any funding agency in the public, commercial, or not-for-profit sectors.
ORCID:

Ga Won Jeon @ https://orcid.org/0000-0002-8206-9727

Hye Jung Choo $@$ https://orcid.org/0000-0003-3941-6989

Yong Uk Kwon @ https://orcid.org/0000-0003-0472-5044

\section{References}

1. Storer SK, Skaggs DL. Developmental dysplasia of the hip. Am Fam Physician 2006;74:1310-6.

2 Lange AE, Lange J, Ittermann T, Napp M, Krueger PC, Bahlmann H, et al. Population-based study of the incidence of congenital hip dysplasia in preterm infants from the Survey of Neonates in Pomerania (SNiP). BMC Pediatr 2017;17:78.

3. Shaw BA, Segal LS. Evaluation and referral for developmental dysplasia of the hip in infants. Pediatrics 2016;138:e20163107.

4. Yang S, Zusman N, Lieberman E, Goldstein RY. Developmental dysplasia of the hip. Pediatrics 2019;143:e20181147.

5. Ortiz-Neira CL, Paolucci EO, Donnon T. A meta-analysis of common risk factors associated with the diagnosis of developmental dysplasia of the hip in newborns. Eur J Radiol 2012;81:e344-51.

6. Clinical practice guideline: early detection of developmental dysplasia of the hip. Committee on Quality Improvement, Subcommittee on Developmental Dysplasia of the Hip. American Academy of Pediatrics. Pediatrics 2000;105(4 Pt 1):896-905.

7. Kolb A, Schweiger N, Mailath-Pokorny M, Kaider A, Hobusch G, Chiari $\mathrm{C}$, et al. Low incidence of early developmental dysplasia of the hip in universal ultrasonographic screening of newborns: analysis and evaluation of risk factors. Int Orthop 2016;40:123-7.

8. Sewell MD, Rosendahl K, Eastwood DM. Developmental dysplasia of the hip. BMJ 2009;339:b4454.

9. Duramaz A, Duramaz BB, Bilgili MG. Does gestational age affect ultrasonographic findings of the hip in preterm newborns? A sonographic study of the early neonatal period. J Pediatr Orthop B 2019;28:107-10.

10. Tuncay IC, Karaeminogullari O, Demirörs H, Tandogan NR. Is prematurity important in ultrasonographic hip typing? J Pediatr Orthop B 2005; 14:168-71.

11. Dogruel H, Atalar H, Yavuz OY, Sayli U. Clinical examination versus ultrasonography in detecting developmental dysplasia of the hip. Int Orthop 2008;32:415-9.

12. Lee J, Spinazzola RM, Kohn N, Perrin M, Milanaik RL. Sonographic screening for developmental dysplasia of the hip in preterm breech infants: do current guidelines address the specific needs of premature infants? J Perinatol 2016;36:552-6. 
13. Graf R. New possibilities for the diagnosis of congenital hip joint dislocation by ultrasonography. J Pediatr Orthop 1983;3:354-9.

14. Omeroğlu H. Use of ultrasonography in developmental dysplasia of the hip. J Child Orthop 2014;8:105-13.

15. Kang YR, Koo J. Ultrasonography of the pediatric hip and spine. Ultrasonography 2017;36:239-51.

16. Brusalis CM, Price CT, Sankar WN. Incidence of acetabular dysplasia in breech infants following initially normal ultrasound: the effect of variable diagnostic criteria. J Child Orthop 2017;11:272-6.

17. Imrie M, Scott V, Stearns P, Bastrom T, Mubarak SJ. Is ultrasound screening for DDH in babies born breech sufficient? J Child Orthop 2010;4:3-8.

18. Hegde D, Powers N, Nathan EA, Rakshasbhuvankar AA. Developmental dysplasia of the hip in preterm breech infants. Arch Dis Child Fetal Neonatal Ed 2020;105:556-8.

19. Quan T, Kent AL, Carlisle H. Breech preterm infants are at risk of developmental dysplasia of the hip. J Paediatr Child Health 2013;49:658-63.

20. D'Alessandro M, Dow K. Investigating the need for routine ultrasound screening to detect developmental dysplasia of the hip in infants born with breech presentation. Paediatr Child Health 2019;24:e88-93.

21. Hussain SM, Ackerman IN, Wang Y, Zomer E, Cicuttini FM. Could low birth weight and preterm birth be associated with significant burden of hip osteoarthritis? A systematic review. Arthritis Res Ther 2018;20:121.

22. Orak MM, Onay T, Gümüştaş SA, Gürsoy T, Muratlí HH. Is prematurity a risk factor for developmental dysplasia of the hip? : a prospective study. Bone Joint J 2015;97-B:716-20.

23. Roovers EA, Boere-Boonekamp MM, Castelein RM, Zielhuis GA, Kerkhoff TH. Effectiveness of ultrasound screening for developmental dysplasia of the hip. Arch Dis Child Fetal Neonatal Ed 2005;90:F25-30.

24. AIUM practice guideline for the performance of an ultrasound examination for detection and assessment of developmental dysplasia of the hip. J Ultrasound Med 2013;32:1307-17.

25. AIUM-ACR-SPR-SRU Practice parameter for the performance of an ultrasound examination for detection and assessment of developmental dysplasia of the hip. J Ultrasound Med 2018;37:E1-5.

How to cite this article: Jeon GW, Choo HJ, Kwon YU. Risk factors and screening timing for developmental dysplasia of the hip in preterm infants. Clin Exp Pediatr 2022;65:262-8. https://doi. org/10.3345/cep.2021.01074 